\title{
Constraints on the Composition of Trojan Asteroid 624 Hektor
}

\author{
Dale P. Cruikshank ${ }^{1,2}$
}

NASA Ames Research Center, MS 245-6, Moffett Field, California 94035-1000

E-mail: dcruikshank@mail.arc.nasa.gov

Cristina M. Dalle Ore

SETI Institute and NASA Ames Research Center, MS 245-6, Moffett Field, California 94035-1000

Ted L. Roush

NASA Ames Research Center, MS 245-3, Moffett Field, California 94035-1000

Thomas R. Geballe

Gemini Observatory, 670 N. A'ohoku Place, Hilo, Hawaii 96720

Tobias C. Owen ${ }^{1}$

Institute for Astronomy, 2680 Woodlawn Drive, Honolulu, Hawaii 96822

Catherine de Bergh ${ }^{1}$

Observatoire de Paris, 4 Place Jules Jannsen, 92195 Meudon Cedex, France

Michele D. Cash

Stanford University, P.O. Box 16637, Stanford, California 94309

William K. Hartmann ${ }^{2}$

Planetary Science Institute, 620 N. $6^{\text {th }}$ Avenue, Tucson, Arizona $85715-8331$

Submitted to Icarus December 12, 2000

Received

Pages: 39

Figures: 7

Tables: 3

1. Guest observer, United Kingdom Infrared Telescope facility (UKIRT)

2. Guest observer, NASA Infrared Telescope Facility (IRTF) 
Proposed Running Head: Composition of Trojan Asteroid Hektor

Address for Correspondence:

\author{
Dale P. Cruikshank
}

Mail Stop 245-6

NASA Ames Research Center

Moffett Field, CA $94035-1000$

dcruikshank@mail.arc.nasa.gov

Phone: 650-604-4244, Fax: 650-604-6779

Key Words: Asteroids, Composition

Mineralogy
Surfaces, Asteroids
Spectroscopy




\section{ABSTRACT}

We present a composite spectrum of Trojan asteroid 624 Hektor, 0.3-3.6 $\mu \mathrm{m}$, which shows that there is no discernible $3-\mu \mathrm{m}$ absorption band. Such a band would indicate the presence of $\mathrm{OH}$ or $\mathrm{H}_{2} \mathrm{O}$ - bearing silicate minerals, or macromolecular carbon-rich organic material of the kind seen on the low-albedo hemisphere of Saturn's satellite Iapetus (Owen et al. 2000). The absence of spectral structure is itself indicative of the absence of the nitrogen-rich tholins (which show a distinctive absorption band attributed to $\mathrm{N}-\mathrm{H}$ ).

The successful models in this study all incorporate the mineral pyroxene $(\mathrm{Mg}, \mathrm{Fe} \mathrm{SiO}$, the composition of hypersthene), which matches the red color of Hektor. Pyroxene is a mafic mineral common in terrestrial and lunar lavas, and is also seen in Main Belt asteroid spectra. An upper limit to the amount of crystalline $\mathrm{H}_{2} \mathrm{O}$ ice (30- $\mu \mathrm{m}$ grains) in the surface layer of Hektor is 3 weight percent. The upper limit for serpentine, as a representative of hydrous silicates, is much less stringent, at 40 percent, based on the shape of the spectral region around $3 \mu \mathrm{m}$. Thus, the spectrum at $3 \mu \mathrm{m}$ does not preclude the presence of a few weight percent of volatile material in the surface layer of Hektor. All of the models we calculated require elemental carbon to achieve the low geometric albedo that matches Hektor. This carbon could be of organic or inorganic origin. By analogy, other D-type asteroids could achieve their red color, low albedo, and apparent absence of phyllosilicates, from compositions similar to the models presented here. 


\section{INTRODUCTION}

The D-type asteroid 624 Hektor is the largest of the jovian Trojan population. It is highly elongated, with maximum and minimum dimensions 300 and $150 \mathrm{~km}$, respectively (Dunlap and Gehrels 1969, Hartmann and Cruikshank 1978, 1980). Infrared thermal emission measurements also show that Hektor's surface has a low geometric albedo of 0.03 (Cruikshank 1977, Hartmann and Cruikshank 1978), while photometry in the eightcolor system shows that it is distinctly red (Zellner et al. 1985). The spectrum of Hektor between 0.3 and $1 \mu \mathrm{m}$ (Jewitt and Luu 1990), and 1.5 and $2.5 \mu \mathrm{m}$ (data presented here) shows no distinctive or diagnostic absorption bands that would indicate specific mineral, ice, or organic surface components. Dumas et al. (1998) recorded segments of the spectrum between 0.9 and $2.4 \mu \mathrm{m}$ and found no clear absorption bands. A spectrum between 0.48 and $0.95 \mu \mathrm{m}$ by Vilas et al. (1993) similarly shows no prominent spectral features (see below). The low albedos and red colors of asteroids and other small bodies in the outer Solar System have often been considered suggestive of the presence of macromolecular carbon-rich surface materials (e.g., Gradie and Veverka 1980, Cruikshank 1987, Cruikshank and Khare 2000). On the other hand, specific spectral matches have been very hard to establish (e.g., Luu et al. 1994, Moroz et al. 1998).

In the quest to understand the origins and compositions of low-albedo bodies, we see Hektor as a key object in the panorama of small, black and red-colored bodies that begins with the satellites of Mars and continues on through the asteroid Main Belt. The question of Hektor's composition arises in the context of its large size and its intermediate location between the asteroid zone and the more distant small bodies. Is Hektor part of a 
continuum of asteroidal bodies of volatile-poor objects that formed in the inner part of the Solar System, or is it a "gateway" object to the more distant realm of volatile-rich planetary satellites and bodies extracted from the two great comet reservoirs (the Kuiper Disk and Oort cloud)? Does Hektor's large size give it sufficient gravity to retard significantly the escape of volatiles? We return to these issues in section IV B.

The characteristic low albedo and red color of Hektor and outer Main Belt asteroids extends through the Hilda objects, the jovian Trojans, and into the outer Solar System, where some planetary satellites, some Centaurs, and some Kuiper Disk objects are very red and of low albedo. In the asteroid Main Belt, low-albedo bodies are mixed in with bodies having higher albedos, but beyond 3.2 AU nearly all asteroids have low albedos.

In addition to variation in redness and albedo, asteroids show differing manifestations of the presence of water. Lebofsky et al. (1990) conducted a search for $\mathrm{H}_{2} \mathrm{O}$ ice and hydrous silicates in low-albedo asteroids using a series of filters across the 3- $\mu \mathrm{m}$ spectral region where these materials absorb. Among the $\mathrm{D}$ asteroids they found no evidence for ice and ambiguous results for hydrous silicates. In a spectral survey with higher spectral resolution of C, P, and D asteroids at $3 \mu \mathrm{m}$, Jones et al. (1990) found clear evidence for water of hydration in low-albedo objects at small heliocentric distances. They further demonstrated that the C-types show decreasing evidence for water of hydration toward larger heliocentric distances, and that the surfaces of the P-and D-types (typically at 3.5 AU) appear to be anhydrous (see section III.A.3 below). Neither do (three of) the lowalbedo satellites of Jupiter show any evidence of $\mathrm{H}_{2} \mathrm{O}$ ice or hydrous minerals (e.g., Luu 
1991, Dumas et al. 1998). Beyond Jupiter, however, several low-albedo satellites of the planets show $\mathrm{H}_{2} \mathrm{O}$ ice in their near-infrared spectra. Phoebe (Saturn), and Nereid (Neptune), are the notable cases that have been reported so far (Owen et al. 2000, Brown et al. 1999a, Brown 2000).

With the exception of Centaurs 5145 Pholus (Cruikshank et al. 1998), 10199 Chariklo (formerly $1997 \mathrm{CU}_{26}$, Brown et al. 1998), most low-albedo asteroids and other small bodies in the outer Solar System (e.g., Barucci et al. 1994, Luu et al. 1994, Dumas et al. 1998) show no diagnostic spectral features in the near-infrared $(1.0-2.5 \mu \mathrm{m})$. Other studies (e.g., Vilas et al. 1994, Barucci et al. 1998) have focused on spectral features in region $0.4-1.0 \mu \mathrm{m}$ that are attributed to iron-alteration minerals indicative of the presence of phyllosilicates.

Jones et al. (1990) proposed that asteroids in the inner parts of the Main Belt had their interior water (or ice) mobilized by the heat from the Sun, while at larger heliocentric distances there was insufficient heat to liquefy any water and hydrolize the minerals. The Trojan asteroids and the outer satellites of Jupiter are clearly in a transition région between the asteroids and small, dark icy bodies such as Phoebe, where ice is clearly present on the surface. It thus becomes interesting to test the hypothesis of Jones et al. (1990) by determining whether or not there is any evidence of ice or hydrated minerals on the Trojan asteroids. 
Water ice can be detected in the spectral region $1.4-2.5 \mu \mathrm{m}$, which is relatively easily observed. However, clear evidence for hydrated minerals comes from a strong absorption band that begins at $2.7 \mu \mathrm{m}$ and extends to about $3.6 \mu \mathrm{m}$, depending upon the presence of $\mathrm{OH}$ in the mineral structure, $\mathrm{H}_{2} \mathrm{O}$ in the mineral lattice (as in the phyllosilicates), and adsorbed molecular $\mathrm{H}_{2} \mathrm{O}$. The latter spectral region is much more difficult to observe because of decreased solar intensity, strong absorption bands in the Earth's atmosphere, and other technical complications.

As spectrometers improve and various technical problems are overcome, the spectral region around $3 \mu \mathrm{m}$ is proving to be important in the spectroscopic characterization of macromolecular organic solids. Notable examples are the low-albedo hemisphere of Iapetus (Owen et al. 2000) and other icy planetary satellites such as Rhea (Dalle Ore et al. 1999, Cruikshank et al. in preparation). In this paper we present a new spectrum of Hektor in the region 2.4-3.6 $\mu \mathrm{m}$. When added to earlier data at shorter wavelengths, these data give some useful constraints on the composition of the asteroid's surface.

\section{NEW OBSERVATIONS}

We report here a new spectrum of Hektor in the range $2.40-3.60 \mu \mathrm{m}$, obtained with the CGS4 spectrometer on the United Kingdom 3.8-m telescope (UKIRT) on Mauna Kea. The unsmoothed spectrum is shown in Figure 1. The 40 lines/mm grating of CGS4 was used in first order with a $1.2 \mathrm{arcsec}$ slit, yielding an intrinsic resolution of $0.005 \mu \mathrm{m}$ at all wavelengths. Two settings of the grating were used, each covering $0.6 \mu \mathrm{m}$, adjusted to give a suitable wavelength overlap around $3.0 \mu \mathrm{m}$. The star BS $2141\left(\mathrm{GO} \mathrm{V}, \mathrm{m}_{\mathrm{V}}=6.12\right)$ 
was observed at comparable airmass and used as a standard. Wavelength calibration was obtained from measurements of argon arc lines in first and second order and is accurate to better than $0.001 \mu \mathrm{m}$. The data we use for model fitting (Figure 2 et seq.) have been highly smoothed by re-binning the data in intervals of $0.06 \mu \mathrm{m}$. For each bin the average value and the standard deviation were calculated and plotted as a data point and an error bar, respectively.

The new data are combined with data at shorter wavelengths from other sources. We use photometry from the eight-color asteroid survey (ECAS) (Zellner et al. 1985), and a spectrum by Vilas et al. (1993) (Figure 2, with enlarged inset). We also use previously unpublished spectrophotometry with the NASA Infrared Telescope Facility (IRTF) in the range $1.6-2.4 \mu \mathrm{m}$ (Table I). The IRTF data were obtained with a circular variable interference filter and a single-detector InSb photometer. The spectrum was observed by mechanically stepping the variable interference filter by a specified wavelength interval, so that in the course of about 15 minutes some 16 individual photometric measurements were made. The standard star, $16 \mathrm{Cyg} \mathrm{B,} \mathrm{a} \mathrm{solar} \mathrm{analog,} \mathrm{was} \mathrm{observed} \mathrm{at} \mathrm{a} \mathrm{comparable}$ airmass and in the same manner.

Table I Log of Observations of 624 Hektor

\begin{tabular}{|l|l|c|c|}
\hline \multicolumn{1}{|c|}{ Object } & \multicolumn{1}{c|}{ Date } & $\begin{array}{c}\text { Mid-exposure } \\
\text { UT }\end{array}$ & Airmass \\
\hline 624 Hektor & 1984 Sept. 7* & 1350 & 1.10 \\
\hline 16 Cyg B & 1984 Sept. 7* & 0624 & 1.18 \\
\hline BS 2141 & 1998 Oct. 28** & 1254 & 1.08 \\
\hline 624 Hektor & 1998 Oct. 28** & 1325 & 1.10 \\
\hline 624 Hektor & 1998 Oct. 28** & 1440 & 1.10 \\
\hline BS 2141 & 1998 Oct. 28** & 1509 & 1.09 \\
\hline
\end{tabular}


* NASA Infrared Telescope Facility, spectrometer using a circular variable interference filter for wavelength separation.

** United Kingdom Infrared Telescope, using the CGS4 spectrometer

In addition, we use JHK photometry of Hektor from Veeder et al. (1983) as a check for consistency in the absolute level (geometric albedo) of the spectrum and its overall shape.

Asteroids in the Main Belt show an increase in flux longward of about $3 \mu \mathrm{m}$, because of their intrinsic thermal emission. At 5 AU heliocentric distance, however, Hektor is sufficiently cold that the thermal flux is an insignificant fraction of the reflected solar flux, and therefore no correction was necessary to produce the final spectrum.

\section{DISCUSSION}

The composite spectrum of Hektor in Figure 2 shows that the principal distinguishing characteristics are the overall low albedo and the increase in reflectance toward longer wavelengths (the red color) to about $2 \mu \mathrm{m}$. Hektor is clearly different from those asteroids that have the hydrous silicate band at $3 \mu \mathrm{m}$, the low-albedo Centaur objects and planetary satellites that show shallow $\mathrm{H}_{2} \mathrm{O}$-ice absorption bands, and the loy-albedo hemisphere of Iapetus with its strong $3-\mu \mathrm{m}$ absorption band attributed to ice plus macromolecular carbon solids (see references above). In view of these differences, we ask what constraints can be placed on Hektor's surface composition, and what options remain. 


\section{A. Compositional Models of Hektor's Surface}

In order to test for surface constituents of particular interest, we first need a general compositional model of the surface, calculated with a rigorous scattering theory and using plausible components. We have calculated several models using the Hapke scattering theory (Hapke 1981) and the complex refractive indices of pyroxene, amorphous carbon, and other materials. Pyroxenes are a group of rock-forming mafic silicates that are common in terrestrial and lunar igneous rocks, in meteorites and asteroids, and have also been found in comet dust (Wooden et al. 2000).

The principal characteristics of Hektor's albedo spectrum that constrain the components and the details of the models include a) the low albedo, the red slope at shorter wavelengths, b) the lack of discrete spectral absorption bands, c) the noise in data in the longest wavelength region, and d) the increase in albedo at wavelengths $<0.45 \mu \mathrm{m}$. Overall, the low albedo is reasonably matched by $\mathrm{Mg}$-rich pyroxene, but in some models we have added carbon (amorphous and graphitic) to lower the albedo to the required levels. Similarly, the red slope is matched in both intimate and spatial models with the materials selected (see further discussion below). The absence of discrete spectral features constrains the presence of olivine, hydrous silicates (see below), $\mathrm{H}_{2} \mathrm{O}$ and other ices, as well as organic solid material used in models of the red and low-albedo surfaces of lapetus (Owen et al. 2000) and Pholus (Cruikshank et al.1998). While the noise in the spectrum at is large at the full resolution of the spectral data, smoothing and averaging demonstrates that there is no strong absorption band near $3 \mu \mathrm{m}$, where $\mathrm{OH}, \mathrm{H}_{2} \mathrm{O}$, and $\mathrm{NH}$ bands occur, and that the reflectance is fairly flat. 
The small increase in albedo at the shortest wavelengths is seen clearly in the data of Zellner et al. (1985) in their compilation of eight-color photometry of over 589 asteroids. A similar increase is seen reliably in only eight other asteroids in their survey; one is another Trojan, and five are Hilda objects. The increase in Hektor's reflectance at the shortest wavelengths may also appear in the spectrum by Jewitt and Luu (1990, Fig. 2e), although their data do not extend shortward of $0.40 \mu \mathrm{m}$. We have not been able to reproduce this feature in any of our models.

The models fall into two categories, those that represent intimate mixtures of all the surface components at the granular level, and those in which the individual surface components are spatially isolated from one another. The fundamental differences arise in the way sunlight interacts with the surface constituents. In the intimate mix models, an individual solar photon scatters from a grain of each mineral or ice before it is emitted from the surface in diffuse reflection. The photon interaction is proportional to the geometrical cross-section of each component, which in turn is dependent upon its relative abundance, grain size, and solid density. In spatial models, an incoming photon scatters from a grain or grains of a single constituent (mineral or ice) only before being emitted from the surface.

It is important to note that we are modeling both the spectral shape and the value of the geometric albedo at every wavelength, thereby constraining the surface composition, 
grain sizes, and nature of surface component mixing better than can be achieved by simple spectrum comparison and matching of normalized spectral reflectance.

The details of some of the models are given in Table II.

Table II. Some Successful Models of 624 Hektor

\begin{tabular}{|c|c|c|c|c|}
\hline Model Type & Component & $\begin{array}{c}\text { Grain size } \\
(\mu \mathrm{m})\end{array}$ & $\begin{array}{l}\text { Weight } \\
\%\end{array}$ & Notes \\
\hline \multirow{3}{*}{$\begin{array}{l}\text { Intimate } \\
\text { Mixture }\end{array}$} & Pyroxene & 30 & 45 & Pyx $0.8 \mathrm{Mg}$, Jena \\
\hline & $\begin{array}{l}\text { Amorphous } \\
\text { carbon }\end{array}$ & 20 & 40 & \\
\hline & Graphite & 50 & 15 & \\
\hline \multirow{3}{*}{$\begin{array}{l}\text { Intimate } \\
\text { Mixure }\end{array}$} & Pyroxene & 30 & 40 & Pyx $0.8 \mathrm{Mg}$, Jena \\
\hline & $\begin{array}{l}\text { Amorphous } \\
\text { carbon }\end{array}$ & 20 & 20 & \\
\hline & Serpentine & 70 & 40 & Mg-rich \\
\hline \multirow{4}{*}{$\begin{array}{l}\text { Intimate } \\
\text { Mixture }\end{array}$} & Pyroxene & 30 & 44 & Pyx $0.8 \mathrm{Mg}$, Jena \\
\hline & $\begin{array}{l}\text { Amorphous } \\
\text { carbon }\end{array}$ & 20 & 11 & \\
\hline & Serpentine & 70 & 30 & Mg-rich \\
\hline & $\mathrm{HCN}$ polymer & 30 & 15 & \\
\hline \multirow{3}{*}{$\begin{array}{l}\text { Intimate } \\
\text { Mixture }\end{array}$} & Pyroxene & 30 & 45 & Pyx $0.8 \mathrm{Mg}$, Jegna \\
\hline & $\begin{array}{l}\text { Amorphous } \\
\text { carbon }\end{array}$ & 20 & 40 & \\
\hline & Iron sulfide & 50 & 15 & \\
\hline \multirow[t]{3}{*}{$\begin{array}{l}\text { Spatial } \\
\text { Distribution }\end{array}$} & Pyroxene & 30 & -- & $\begin{array}{l}\text { Pyx } 0.8 \mathrm{Mg}, 30 \% \\
\text { surface coverage }\end{array}$ \\
\hline & $\begin{array}{l}\text { Amorphous } \\
\text { carbon }\end{array}$ & 30 & - & $\begin{array}{l}20 \% \text { surface } \\
\text { coverage }\end{array}$ \\
\hline & Serpentine & 30 & - & $\begin{array}{l}50 \% \text { surface } \\
\text { coverage }\end{array}$ \\
\hline
\end{tabular}


Table III Sources of Optical Constants

\begin{tabular}{|l|l|l|}
\hline \multicolumn{1}{|c|}{ Material } & \multicolumn{1}{c|}{ Source } & \multicolumn{1}{c|}{ Notes } \\
\hline Olivine & Lucey 1998 & Extends only to 2.5 $\mu \mathrm{m}$ \\
\hline Olivine (Fo50) & Univ. of Jena web site* & $\mathrm{Mg}(0.8) \mathrm{Fe}(1.2) \mathrm{SiO}_{4}$ \\
\hline Pyroxene & Univ. of Jena web site* & $\begin{array}{l}\mathrm{Mg}, \mathrm{Fe} \mathrm{SiO3} \mathrm{(various} \\
\text { proportions of } \mathrm{Mg} \text { and } \mathrm{Fe} \text { ) }\end{array}$ \\
\hline Murchison organic extract & Khare et al. 1994a & \\
\hline Triton tholin & Khare et al. 1994b & $\begin{array}{l}\text { Analysis in McDonald et al. } \\
1994\end{array}$ \\
\hline Ice tholin I & Khare et al. 1993 & $\begin{array}{l}\text { Analysis in McDonald et al. } \\
1996\end{array}$ \\
\hline Allende meteorite & This paper ${ }^{* *}$ & Calculated by T. Roush \\
\hline Serpentine & Roush 1987 & Mg-rich serpentenite \\
\hline $\mathrm{H}_{2} \mathrm{O}$ ice & Ted Roush & Hexagonal, $\mathrm{T}=100 \mathrm{~K}$ \\
\hline FeS & Pollack et al. 1994 & Used in place of Fe \\
\hline $\mathrm{HCN}$ polymer & Khare et al. 1994a & \\
\hline
\end{tabular}

* http://www.astro.uni-jena.de/Group/Subgroups/Labor/Labor/silicates.html

** see section III.A.6.

With the information in Table II, the intimate mixture models are self-explanatory.

We do not propose that these models accurately reflect the composition of Hektor's surface (although one of them might); instead, they serve as points of departire for the investigation of the presence of ices, hydrous silicates, and organic solids.

\section{A. 1. Mafic Silicates}

We show in Figure 3 that the general features of the Hektor spectrum can approximately be matched with a mixture of Mg-rich pyroxene and elemental carbon (a mixture of 
graphite and amorphous $\mathrm{C}$ ). In this model, the pyroxene provides the overall shape of the spectrum, while the carbon decreases the albedo to the level observed on Hektor.

Pyroxene and olivine are found in numerous asteroid spectra, notably the S-types (e.g., Gaffey et al. 1989), and both could contribute to the low albedo of Hektor. Both minerals have diagnostic spectral features between 0.8 and $2.3 \mu \mathrm{m}$, but these bands are broadened and subdued when the minerals occur in soils with particle sizes $>\sim 200 \mu \mathrm{m}$ (e.g., Crown and Pieters 1987). Furthermore, Moroz and Amold (1999) show that the presence of a material of neutral reflectance (pyrrhotite in their experiments) affects the band contrasts of these minerals and thereby influences abundance determinations. Several studies have shown the effect of temperature variations on the spectral signature of mafic silicates (e.g. Roush 1984, Singer and Roush, 1985, Roush and Singer 1987). Recent efforts suggest that this effect may be more pronounced than originally reported (e.g., Hinrichs et al. 1999a,b 2000, Schade and Wäsch 1999, Moroz et al. 2000). Although these variations may be most important in the interpretation of the mineralogy of the S-type asteroids, the effects of temperature on the complex refractive indices used in this work should be investigated.

The complex refractive indices required in the Hapke scattering calculations are available from two sources known to us. The values derived by Lucey (1998) extend in wavelength only to $2.5 \mu \mathrm{m}$, while values given by the Jena group on their web site extend much further. We have made model calculations with the Lucey values over the range they cover, but the models we show here use the Jena values; differences in the regions of 
overlap are negligible in the current work. Our principal successes in modeling Hektor's reflectance come with the $\mathrm{Mg}$-rich pyroxene ( $80 \% \mathrm{Mg}, 20 \% \mathrm{Fe}$ ), which has the composition of hypersthene. We have also used pyroxenes from the Jena collection with $60 \%$ and $40 \% \mathrm{Mg}$, as shown in Figure 5. Among other things, the models in Fig. 5 demonstrate that the more $\mathrm{Mg}$-rich pyroxenes are generally redder in the region 0.3-2 $\mu \mathrm{m}$.

Models in which olivine (Fo 90, or forsterite, the Mg-rich end-member olivine) data from Lucey (1998) were included together with pyroxene, graphite, and FeS, provided a satisfactory match to the Hektor spectrum out to the $2.5 \mu \mathrm{m}$ limit of the Lucey data. The models are trending upward toward longer wavelengths, away from the trend of the 2.5$3.6 \mu \mathrm{m}$ data for Hektor.

\section{A. 2. $\mathrm{H}_{2} \mathrm{O}$ Ice}

At visual wavelengths all ices and frosts are highly reflective and lack color. Consequently, the presence of ice on a planetary surface generally raises the albedo above that arising from minerals and organic solids. In addition, there are three diagnostic features of $\mathrm{H}_{2} \mathrm{O}$ ice in our spectral region in the form of absorption bands at $1.5,2.0$, and $3 \mu \mathrm{m}$. Also, the ice decreases the red slope in the visible region by raising the albedo. From the several models we calculated for various grain sizes and weight percentages of $\mathrm{H}_{2} \mathrm{O}$ ice, we conclude that if the grain size of $\mathrm{H}_{2} \mathrm{O}$ ice is $100 \mu \mathrm{m}$, the upper limit in our model fits to the Hektor spectrum is $5-7$ weight percent. For $30-\mu \mathrm{m}$ ice grains the slope decreases even more rapidly with increasing quantities, and when 3 
weight percent $\mathrm{H}_{2} \mathrm{O}$ is added, the fit is poor. An upper limit of $30-\mu \mathrm{m}$ ice grains is thus 3 weight percent.

In Figure 4 we show three models that include $\mathrm{H}_{2} \mathrm{O}$ ice. Olivine has been added to help keep the albedo close to the Hektor data in the short wavelength region, but olivine has the property of raising the albedo for $\lambda>2.2 \mu \mathrm{m}$.

\section{A. 3. Phyllosilicates}

A body of telescopic and laboratory studies has led to the supposition of a genetic relationship between the low-albedo asteroids and carbonaceous meteorites (e.g., Gaffey et al. 1989, Cruikshank 1997). The carbonaceous meteorites contain phyllosilicates, predominantly iron-bearing species (Bunch and Chang 1980, Zolensky and McSween 1988). The lattice-bound $\mathrm{OH}$ and interlayer trapped $\mathrm{H}_{2} \mathrm{O}$ in the phyllosilicates gives rise to a prominent absorption band in the reflectance and transmission spectra of the $\mathrm{CO}, \mathrm{CI}$, and CM meteorites, centered at $3 \mu \mathrm{m}$ (e.g., Hiroi et al. 1996; Calvin and King 1997). Calvin and King (1997) found that the strong $3-\mu \mathrm{m}$ band in $\mathrm{CI}$ and $\mathrm{CM}$ meteorites was due to several mineral phases (combinations of $\mathrm{Fe}$ and $\mathrm{Mg}$ phyllosilicates). In the case of Murchison, heating to $600 \mathrm{C}$ greatly reduces the strength of the 3- $\mu \mathrm{m}$ band, and heating to $900 \mathrm{C}$ removes it entirely (Hiroi et al. 1996).

Hydrated lattice layer silicates are also found in some interplanetary dust particles (IDPs); smectite-bearing IDPs are predominant, but serpentine-bearing IDPs also occur (Bradley 1988). Micrometeorites, which represent the principal mass influx of meteoric material 
to the Earth at the present time, are primarily carbonaceous in nature and also contain hydrous minerals (Maurette et al. 1996).

Because of the presumed genetic link between the carbonaceous meteorites, some classes of IDPs and micrometeorites, and the asteroids of low albedo, the presence or absence of the $3-\mu \mathrm{m}$ absorption in the reflectance spectra of asteroids is of special interest. This is particularly true because of the paucity of any other prominent and readily interpretable spectral feature observed so far in these asteroids (e.g., Jones et al. 1990). We have therefore used a serpentine in our modeling calculations for Hektor. We have complex refractive indices for only one such mineral, a Mg-rich serpentine (Roush 1987, p. 25, specimen identified as serp01). Spectra of other hydrous silicates can be found in Calvin and King (1997).

The reflectance of serpentine shows a change in slope at $-2 \mu \mathrm{m}$, as well as a strong absorption band at $3 \mu \mathrm{m}$. In calculations with grains larger than $50 \mu \mathrm{m}$ the strong band at $3 \mu \mathrm{m}$ becomes shallow. Our models with pyroxene and carbon can accommodate $\sim 40$ weight percent of serpentine with grain size $70 \mu \mathrm{m}$ (Figure 5). Roush's tabulation of the chemical analysis of this serpentine specimen (1987, Table 3 ) shows that the loss-onignition value is 14.5 percent; this means that the volatiles $\left(\mathrm{H}_{2} \mathrm{O}\right.$ and others $)$ lost during pyrolysis amounted to 14.5 percent of the weight of the sample. Thus, if 40 percent of Hektor's surface material were to consist of this serpentine, the bulk volatile content of the surface would be 5.8 percent. This value is comparable to the maximum amount of 
$\mathrm{H}_{2} \mathrm{O}$ ice that can be accommodated by the models of Hektor's spectrum (see III.A.2 above). We return in Section IV.B to the significance of volatiles in Hektor's regolith.

\section{A.4. The Role of Carbon in the Models}

We showed above in Figure 3 that a simple intimate mixture of a $\mathrm{Mg}$-rich pyroxene and elemental carbon provides an approximate match to the spectrum of Hektor. The carbon in this model could be derived from fully dehydrogenated organic matter, or it could have some other origin. In contrast, the surface of Centaur object 5145 Pholus has a steep red slope (steeper than Hektor) and albedo level (as well as a discrete absorption band at 2.27 $\mu \mathrm{m})$ that are modeled with a mixture that includes macromolecular organic carbon and solid methanol $\left(\mathrm{CH}_{3} \mathrm{OH}\right)$ (Cruikshank et al. 1998). Pholus appears to require organic carbon to match the overall spectral shape, particularly in the region $0.4-1.0 \mu \mathrm{m}$. This view that was adopted by three independent groups who studied the spectrum shortly after this object (originally designated $1992 \mathrm{AD}$ ) was discovered (Mueller et al. 1992, Binzel 1992, Fink et al. 1992). A surface containing macromolecular organic carbon and a light hydrocarbon like methanol could be highly (or completely) reduced by heating, cosmic ray bombardment, and other space-weathering processes, given sufficient time, although we have no assurance that there could have been sufficient solar heating at 5 AU to have any effect.

Hektor can also be modeled satisfactorily with a mixture of pyroxene, serpentine, hydrogen cyanide polymer, and organic carbon in the form of a terrestrial kerogen (see below). At the level of the present modeling study, we cannot distinguish between 
organic and inorganic carbon. Furthermore, it is possible that carbon could be replaced entirely by a very low-albedo mineral of neutral reflectance.

\section{A.5. Macromolecular Carbon-Bearing Material}

We have incorporated two kinds of macromolecular carbon-bearing materials in our models; a solid polymer of hydrogen cyanide (HCN) (Khare et al. 1994a), and four varieties of the synthetic macromolecular complex called tholin.

Owen et al. (2000) have successfully modeled the albedo spectrum of the low-albedo (leading) hemisphere of Iapetus between 0.4 and $4 \mu \mathrm{m}$, using an intimate mixture of the material known as Triton tholin (see Table IV), $\mathrm{H}_{2} \mathrm{O}$ ice, and amorphous carbon. The tholin provides the steep upward slope (toward the red) and a very strong absorption band at $3 \mu \mathrm{m}$ seen in the Iapetus spectrum. The carbon adjusts the albedo downward to the Iapetus level, and the $\mathrm{H}_{2} \mathrm{O}$ ice matches three absorption bands of moderate strength. The low albedo and red color of Iapetus' leading hemisphere caused us to try similar models for Hektor, but we quickly learned that the strong $3-\mu \mathrm{m}$ band in Triton tholin severely limits the amount of this material that can be present on the asteroid. Our models show that no more than about five weight percent of Triton tholin (grain size $100 \mu \mathrm{m}$ ) can be present in the surface layer of Hektor.

We noted above that the spectrum of 5145 Pholus can be matched with an intimate mixture of several components that includes Titan tholin (see Table IV). We calculated models with intimate mixtures of Titan tholin paired with FeS, olivine, or pyroxene, but 
in all cases the resulting albedo was too low in the region beyond $2.5 \mu \mathrm{m}$. Furthermore, the slope of the albedo in the UV-visible region failed to match the observations.

Two other tholins, both of which were produced by the irradiation of ice mixtures, and denoted ice tholins I and II (see Table IV) were tried in various combinations with pyroxene, but the models all failed to achieve the shape of the Hektor spectrum. All of the tholins show strong absorption at $3 \mu \mathrm{m}$, and absence of this band in the spectrum of Hektor strongly limits the quantity that could be present.

Table IV Tholins

\begin{tabular}{|l|l|l|l|}
\hline \multicolumn{1}{|c|}{ Name } & \multicolumn{1}{|c|}{ Starting Mixture } & Energy Source & \multicolumn{1}{c|}{ References } \\
\hline & & & \\
\hline Triton tholin & Gaseous $\mathrm{N}_{2}: \mathrm{CH}_{4}(99.9: 0.1)$ & Plasma discharge & McDonald et al. 1994 \\
\hline Titan tholin & Gaseous $\mathrm{N}_{2}: \mathrm{CH}_{4}(9: 1)$ & Plasma discharge & $\begin{array}{l}\text { Khare et al. 1984, } \\
\text { McDonald et al. 1994 }\end{array}$ \\
\hline Ice tholin I & $\mathrm{H}_{2} \mathrm{O}: \mathrm{C}_{2} \mathrm{H}_{6}(6: 1)$ & Plasma discharge & $\begin{array}{l}\text { Khare et al. 1993, } \\
\text { McDonald et al. 1996 }\end{array}$ \\
\hline Ice tholin II & $\begin{array}{l}\mathrm{H}_{2} \mathrm{O}: \mathrm{CH}_{3} \mathrm{OH}: \mathrm{CO}_{2}: \mathrm{C}_{2} \mathrm{H}_{6} \\
(80: 16: 3.2: 0.8)\end{array}$ & Plasma discharge & McDonald et al. 1996 \\
\hline
\end{tabular}

Spectra of other macromolecular carbon-bearing materials are available (e.g., Cloutis et al. 1994, Moroz et al. 1998), although to our knowledge the complex refractive indices have not been determined for these materials. Refractive indices are available for kerogen (Khare et al. 1994a), and while we have experimented with kerogen-bearing models, we do not include them here because this material is of terrestrial biological origin. Some macromolecular materials, particularly the mostly dehydrogenated organic 
solids (e.g., the anthraxolites shown by Moroz et al. 1998) may not be precluded from presence on Hektor. More hydrogenated materials (asphaltites and kerites) have very strong spectral absorptions surrounding the 3.4- $\mu \mathrm{m} \mathrm{C}-\mathrm{H}$ bands, and cannot be present in significant amounts on Hektor. We see no evidence for the 3.4- $\mu \mathrm{m}$ band complex on Hektor, although the noise in the data is rather high. Several studies of the dehydrogenation of complex organics by energy deposition (e.g., Thompson et al. 1987, Strazzulla et al. 1988), with a consequent darkening and removal of spectral features, may be relevant to the Hektor case, although the specifics and details remain for future investigators.

\section{A.6 Comparison With Meteorites}

It is reasonable to consider carbonaceous meteorites and their constituents, as well as other low-albedo meteorites as possible components of Hektor's surface. Several possibilities exist, including the well-studied Allende, Murchison, and Orgueil, and the carbon-bearing urelites. Some shocked ordinary chondrites are also very black, and deserve consideration. The carbonaceous meteorites represent a wide range of compositions, histories, and degrees of hydration; the latter is evident in the presence or absence of the 2.9- $\mu \mathrm{m} \mathrm{OH}$ and $\mathrm{H}_{2} \mathrm{O}$ band complex (e.g., Salisbury et al. 1991).

In order to include the Allende meteorite in the Hapke scattering models described above, the complex refractive indices were calculated from a reflectance spectrum of powdered meteorite (chondrules $+\mathrm{CAI}+$ matrix) for which the particle sizes are known, by $\mathrm{T}$. $\mathrm{L}$. Roush, using the Kramers-Kronig approach (see Appendix A). 
Figure 6 shows biconical reflectance spectra of a pulverized sample of Murchison (CM2), an acid-insoluble organic residue from Murchison, and the Allende powder noted above. The spectral reflectance of Allende in the region 3.0-3.6- $\mu \mathrm{m}$ is smooth and sloped slightly downward toward long wavelengths, in a way that is not strongly different from Hektor. It is also red in the photovisual spectral region, similar to the asteroid, and has shallow absorption bands near 1.05 and $1.9 \mu \mathrm{m}$ (olivine and pyroxene). The weak absorption centered at $-2.9 \mu \mathrm{m}$ is consistent with the presence of a very small percent of hydrous silicates present in $\mathrm{CV}$ meteorites, or perhaps adsorbed $\mathrm{H}_{2} \mathrm{O}$ in the powdered specimen (see also Salisbury et al. 1991).

The bulk Murchison material in Figure 6 is also red at short wavelengths, and apart from some absorption bands, the reflectance rises continuously toward longer wavelengths. Murchison presents a distinct absorption band at $0.8 \mu \mathrm{m}$, a shallow band at $2 \mu \mathrm{m}$, and a distinct water of hydration band at $-2.7 \mu \mathrm{m}$. An inflection at $3.4 \mu \mathrm{m}$ in the broad hydrous silicate band occurs at the position of the $\mathrm{C}-\mathrm{H}$ stretching mode complex characteristic of aliphatic hydrocarbons. Aliphatic hydrocarbons are found in the Murchison meteorite (Cronin et al. 1988), although Salisbury et al. (1991) caution that organic vapors from laboratory vacuum pumps can also find their way to meteorite samples and give a false spectral signature. The bulk Murchison and Allende samples shown in Figure 6 were both prepared and stored in the same manner and at the same 
time; the absence of the $\mathrm{C}-\mathrm{H}$ signature in Allende certifies that the spectral signature in Murchison is intrinsic to the material and not due to laboratory contamination'.

Bulk Murchison, with its strong water of hydration signature is clearly no match for the spectrum of Hektor, but studies of dehydrated Murchison meteorite (Hiroi et al. 1996) show that the band disappears upon heating, as noted above.

The acid-insoluble organic residue extracted from the Murchison meteorite by Alaerts et al. (1980) has a different shape from the bulk Murchison, and the strong hydrous silicate signature centered near $2.7 \mu \mathrm{m}$ is gone. The $3.4-\mu \mathrm{m}$ signature of aliphatic hydrocarbons remains.

Additional reflectance spectra $(0.35-2.5 \mu \mathrm{m})$ of powdered meteorites are given by Gaffey (1976), and transmission spectra $(2.5-25 \mu \mathrm{m})$ have been published by Sandford (1984, 1993). Salisbury et al. (1991) show many meteorite spectra in biconical reflectance, 2.5$13.5 \mu \mathrm{m})$. Gaffey shows a urelite and four shock-blackened chondrites; all have red slopes in the short wavelength region, an absorption band at $0.9 \mu \mathrm{m}$, and gradually increasing slopes toward longer wavelengths. In Sandford's (1993) spectra of urelites, there is a weak water band at $3 \mu \mathrm{m}$, but Sandford attributes it to adsorbed water in the $\mathrm{KBr}$ pellets used in the process of obtaining transmission spectra. The shocked ordinary chondrites do not contain water or hydrous silicates, and should not have a 3- $\mu \mathrm{m}$ band.

\footnotetext{
'The spectra in Figure 6 were obtained in the laboratories of R. N. Clark and J. W. Salisbury, with the assistance of $\mathrm{K}$. Uchida.
} 
In summary of this section, there is no direct spectroscopic link between the surface of Hektor and any of the very low-albedo meteorites studied so far, although small amounts of dehydrated carbonaceous meteorites (e.g., Murchison) are not completely excluded.

\section{A.7 Iron Sulfide}

Metallic iron is apparently a fundamental contributor to the optical properties of the lunar surface, and it arises on mature lunar soil grains through the interaction of the solar wind with $\mathrm{FeO}$ in lunar minerals (Pieters et al. 2000). The red coloration of S-type (and the A subtype) asteroids has been attributed by some investigators as a result of the presence of metallic Fe in the surface materials (see Gaffey et al. 1989). These irradiation effects are less important at the large heliocentric distances of the outer asteroid belt and the Trojan regions, but the effects of $\mathrm{Fe}^{0}$ on the optical properties of such asteroids should be examined further. In particular, the effects of micrometeorite impacts on the segregation and reduction of iron in regolith grains of distant asteroids require study.

We tried a series of models using the optical constants of FeS (as a replacement for metallic $\mathrm{Fe}$ ) because of the low albedo and reddish color of this material. We, find no compelling reason to prefer $\mathrm{FeS}$ to the color and albedo properties of the other materials used in different models. 


\section{B. Spatial Models}

We computed a number of models in which the selected components were isolated from one another in the spatial sense, as described in section III.A. The images of asteroid 433 Eros from the NEAR-Shoemaker spacecraft have shown that the spatial segregation of different surface materials on an asteroid does indeed occur. Regions of the surface could consist of materials excavated from depth by recent impact events, or different materials that are deposited from an external source, to mention only two plausible examples giving rise to such a situation. In such models, the number of free parameters increases over the intimate mixture models, and for the present purposes we show only two of the better models (Figure 7) with pyroxenes, amorphous carbon, and serpentine. As can be seen in Figure 7, neither model fits the Hektor spectrum as well as the intimate mixture models with the same components, particularly for the pyroxene with 80 percent Mg. The sensitivity to the concentration of serpentine does not change significantly compared to the intimate mixture models.

\section{CONCLUSIONS}

\section{A. Results of the Observations and Modeling}

\section{1}

We have shown that the low albedo and the shape of the reflectance spectrum of Hektor can be matched by models incorporating pyroxene and carbon, as well as by various combinations of these materials plus organic solids (kerogen) and $\mathrm{HCN}$ polymer. None of our models is regarded as unique, but the family of models that match the spectrum of Hektor to a reasonable degree allow us to put constraints on the composition of the surface layer of this body. 
The absence of water ice at concentrations greater than a few percent distinguishes Hektor from several other low-albedo objects in the outer solar system. Phoebe, Nereid, some Centaurs, and some Kuiper Disk objects show absorption bands of $\mathrm{H}_{2} \mathrm{O}$ ice (references cited earlier, plus Brown et al. 1999b). Spectra of the three irregular satellites of Jupiter show no evidence of $\mathrm{H}_{2} \mathrm{O}$ ice absorptions in the 1-2.5 $\mu \mathrm{m}$ spectral range (Dumas et al. 1998, Brown 2000), but spectra have not yet been obtained at longer wavelengths.

The 3- $\mu \mathrm{m}$ spectral region is diagnostic not only of $\mathrm{H}_{2} \mathrm{O}$ ice, but of $\mathrm{H}_{2} \mathrm{O}$ associated with phyllosilicates, and in the hydrous silicates. Our models show that the hydrous silicate serpentine, which originates from the hydrothermal alteration of olivine, could exist on Hektor in concentrations up to about $40 \%$ and still be compatible with the observational data. It appears that the carbon used in the models might quench the 3- $\mu \mathrm{m}$ band of bound $\mathrm{H}_{2} \mathrm{O}$, masking its possible presence in small quantities.

The data presented here preclude large amounts of certain organic materials oh Hektor, notably the material that has a strong $3-\mu \mathrm{m}$ band and fits the spectrum of the low-albedo hemisphere of Iapetus very well. Macromolecular carbon-bearing material with a kerogen-like structure and certain other organic solids are not precluded, provided that they do not have strong 3- $\mu \mathrm{m}$ absorption bands. The low albedo throughout the spectrum is a strong indicator of carbon as a surface component, but we do not know the origin of 
that carbon. Our models use elemental carbon, which on Hektor could be derived from the dehydrogenation of organic carbon.

We also showed that the Allende meteorite is not a good spectral analog for Hektor, nor do Murchison, the urelites, or shock-blackened ordinary chondrites provide a spectral match. Small amounts of these materials are not precluded from Hektor's surface, but they are not the spectrally dominant component.

The question of the surface composition of Hektor has not yet been solved, but the study presented here demonstrates that $\mathrm{H}_{2} \mathrm{O}$ ice is not abundant, and that dehydrogenated organic carbon and a significant amount of water bound in minerals may be present.

The possibility that as much as 40 weight percent of Hektor's surface material could be a hydrous silicate without its presence being revealed through the $3-\mu \mathrm{m}$ absorption band carries important implications for other low-albedo asteroids in the main belt and in the Trojan populations. It is possible that the trend of decreasing 3- $\mu \mathrm{m}$ absorption band strength with heliocentric distance in the low-albedo asteroids (Jones et al. 1990) is a consequence of an increased abundance of rèduced carbon.

Spectra of comets show the C-H stretching mode spectral features at $3.4 \mu \mathrm{m}$ in emission. The same bands could, in principle, appear in absorption in the reflectance spectrum of a solid comet nucleus or other volatile-rich body. The noise in our data restricts the possibility of finding the 3.4- $\mu \mathrm{m} \mathrm{C-H} \mathrm{stretching} \mathrm{mode} \mathrm{absorption} \mathrm{bands} \mathrm{on} \mathrm{Hektor,} \mathrm{but}$ 
data of higher quality should eventually enable the determination of a meaningful upper limit.

Concerning the suggestion by Gradie and Veverka (1980) that Hektor (as a representative of small bodies of low albedo) may be colored by macromolecular carbon-bearing materials, we find no direct support for this hypothesis because a common igneous mineral (pyroxene) will suffice to provide the color. However, we cannot rule out or exclude the possibility that organic material is the cause of the red color and low albedo.

\section{B. The Nature of Hektor}

The observations and modeling reported here bring us back to the larger scale paradox of the distribution of detectable $\mathrm{H}_{2} \mathrm{O}$ ice, and volatiles in general, on the surfaces of small and modest-sized bodies in the outer solar system. It is generally accepted that small bodies beyond the outer belt or the Trojan zone are potential comets. Like 2060 Chiron, 10199 Chariklo, and other such bodies, they contain ice that can produce coma phenomena if they approach close enough to the sun. As noted above, recent observations show ice in on their surfaces. What physical processes control the presence or absence of exposed ice, and is there a consistent set of unifying principles that can be identified? Some of those principles may include the following (partly adapted from Hartmann, 1980):

- The primordial low-albedo, outer solar system material usually contained ices and volatiles, having condensed at low temperature. The putative outward migration of the 
giant planets after their formation, as well as the effects of the faint young Sun, will have affected the distribution of ices in these bodies, but in ways that cannot currently be quantified.

- This water ice was mobilized in the low-albedo asteroids of the outer belt by solar heating and some of the $\mathrm{H}_{2} \mathrm{O}$ was locked in surface material as water of hydration.

- Water ice was also mobilized in many outer solar system satellites by intemal heating, associated either with large size or tidal flexing. In at least some cases, such as Europa, Ganymede, Enceladus, and others, $\mathrm{H}_{2} \mathrm{O}$ ice rich surface layers were created.

- Competing with these processes, hypervelocity impact gardening tends to vaporize any ice that was mixed into surface layers, leaving behind the lower-albedo non-volatile materials. Sputtering by solar wind and cosmic rays, as well as other ablation processes may also be significant.

- On "pure" ice crusts, impact gardening (and other ablation processes) causes gradual darkening and ice depletion (as can be seen on Callisto, where recent craters'penetrate through a dark layer into fresh ice, but old craters are darkened). Ice can added to the surface material by sporadic impacts big enough to tap the "pure" ice layers beneath the ice-depleted, gardened regolith, and maintain some ice content in the regolith mix, as on Callisto. 
- On some primordial, smaller interplanetary bodies, such as Hektor and smaller objects beyond the outer belt, hypervelocity impact gardening devolatilizes the spectroscopically accessible surface layers fairly rapidly. Perhaps Hektor has no "pure" near-surface layer to add fresh ice during gardening, thus leaving no spectroscopic trace of the volatile content. Other bodies (e.g., Chiron, Nereid, Phoebe) may have near-surface ices that can recharge the surface regolith to produce a detectable ice signature

- The most likely interplanetary bodies on which to see spectral evidence of ices (as well as cometary activity) might therefore be those whose orbits have recently changed and brought them closer to the sun, where warming moves mobilizes volatiles and brings them into the surface layers.

Beyond impact gardening, sputtering, and outward migration of the planets after formation, other factors, yet unidentified or understood, may eventually rise to a level of significance in explaining the trends and irregularities in the compositions and surface processing of small bodies in the middle and outer Solar System.

\section{ACKNOWLEDGEMENTS}

UKIRT is operated by the Joint Astronomy Centre on behalf of the U.K. Particle Physics and Astronomy Research Council. The IRTF is operated by the University of Hawaii for NASA. We thank Dr. B. N. Khare for making available the optical constants of various materials in advance of publication. We thank the UKIRT and IRTF staffs for their support of this work. TLR recognizes support of RTOP 344-30-30-01 from NASA's 
Planetary Geology and Geophysics Program. DPC recognizes support of RTOP 344-3220-01 from NASA's Planetary Astronomy Program.

\section{APPENDIX A}

\section{Deriving Optical Constants of Allende}

Clark and Roush (1984) first discussed the use of measured reflectance and Hapke scattering theory (Hapke, 1993) to estimate the absorption coefficients of the material. The general approach is to model the measured reflectance using Hapke theory. This requires some independent knowledge of the grain size, certain assumptions regarding the behavior of the real index of refraction and scattering behavior of the material, and iteratively varying the imaginary index of refraction until the model spectrum reproduces the measured spectrum to some specified level of precision. Calvin and Clark (1991) used this approach to estimate the absorption coefficients for three carbonaceous chondrites, and two enstatite chondrites. More recently, Lucey (1998) similarly derived the absorption coefficients for a suite of olivines and pyroxenes. Here we use this approach to derive the optical constants for Allende meteorite.

1

We began with the reflectance spectrum covering the $0.26-4.01 \mu \mathrm{m}$ region. This sample was measured at the USGS spectroscopy laboratory with an effective viewing geometry having incidence, emittance, and phase angles of $0^{\circ}, 30^{\circ}$, and $30^{\circ}$, respectively. The sample consisted of particles that passed through a sieve with $125 \mu \mathrm{m}$ openings and were retained by a sieve having $90 \mu \mathrm{m}$ openings. We used the median particle size $(107.5 \mu \mathrm{m})$ for our final results, although we did investigate both extremes of particle size. We 
estimated the real index of refraction, at $0.56 \mathrm{~mm}$, as 1.7400 by reviewing the mineralogical components of Allende and calculating an average value; weighted by mineral abundance. Initially we solved for the imaginary index by assuming the real index is constant over the wavelength region. Using these initial estimates of the imaginary index, we used a subtractive Kramers-Kronig approach to solve for the wavelength dependent nature of the real index. We then used these revised values for the real index in another iteration to solve for the imaginary index by fitting the measured reflectance. We continued these iterations until there was little change in either the real or imaginary indices of refraction. We found that within two iterations using the Kramers-Kronig analysis the imaginary index changed by less than four parts in $10^{5}$ and the real index changed by less than three parts in $10^{3}$. The greatest variation in the imaginary index associated with assumptions about grain size is $\sim 40 \%$ when comparing the results for the smallest and largest grain sizes; $\sim 15 \%$ when comparing the largest and median grain size; and $\sim 22 \%$ when comparing the smallest and median grain size. Our use of the median grain size suggests errors in the imaginary index on the order of $20 \%$.

\section{REFERENCES}

Alaerts, L., R. S. Lewis, J-I Matsuda, and E. Anders 1980. Isotopic anomalies of noble gases in meteorites and their origins - VI. Presolar components in the Murchison C2 chondrite. Geochim. Cosmochim. Acta 44, 189-209.

Barucci, M. A., M. Lazzarin, T. Owen, C. Barbieri, and M. Fulchignoni 1994. Nearinfrared spectroscopy of dark asteroids. Icarus 110, 287-291.

Barucci, M. A., A. Doressoundiram, M. Fulchignoni, M. Florczak, M. Lazzarin, C. Angeli, and D. Lazzaro 1998. Search for aqueously altered materials on asteroids. Icarus 132, 388-396.

Binzel, R. 1992. The optical spectrum of 5145 Pholus. Icarus 99, 238-240. 
Bradley, J. P. 1988. Analysis of chondritic interplanetary dust thin-sections. Geochim. Cosmochim. Acta 52, 889-900.

Brown, M. E. 2000. Near-infrared spectroscopy of centaurs and irregular satellites. Astron. J. 119, 977-983.

Brown, R. H., D. P. Cruikshank, Y. J. Pendleton, and G. J. Veeder 1998. Identification of water ice on the Centaur $1997 \mathrm{CU}_{26}$. Science 280, 1430-1432.

Brown, R. H., D. P. Cruikshank, and Y. J. Pendleton 1999a. Water ice on Kuiper belt object $1996 \mathrm{TO}_{66}$. Astrophys. J. 519, L101-L104.

Brown, R. H., D. P. Cruikshank, Y. J. Pendleton, and G. J. Veeder 1999b. Water ice on Nereid. Icarus 139, 374-378.

Bunch, T. E., and S. Chang 1980. Carbonaceous chondrites--II. Carbonaceous chondrite phyllosilicates and light element geochemistry as indicators of parent body processes and surface conditions. Geochim. Cosmochim. Acta 44, 1543-1577.

Calvin, W.M. and R.N. Clark (1991) Modeling the reflectance spectrum of Callisto 0.25 to $4.1 \mu \mathrm{m}$, Icarus $89,305-317$.

Calvin, W. M., and T. V. V. King 1997. Spectral characteristics of iron-bearing phyllosilicates: Comparison to Orgueil (CI1), Murchison and Murray (CM2). Meteorit. Planet. Sci. 32, 693-701.

Clark, R.N. and T.L. Roush (1984) Reflectance spectroscopy: Quantitative analysis techniques for remote sensing applications, J. Geophys. Res. 89, 6329-6340.

Cloutis, E. A., M. J. Gaffey, and T. F. Moslow 1994. Spectral reflectance properties of carbon-bearing materials. Icarus 107, 276-287.

Cronin, J. R., Pizzarello, S., and Cruikshank, D. P. 1988 Organic matter in carbonaceous chondrites, planetary satellites, asteroids and comets. In Meteorites and the Early Solar System (J. F. Kerridge and M. S. Matthews, Eds.), pp. 819-857. Univ. of Arizona Press, Tucson.

Crown, D. A., and C. M. Pieters 1987. Spectral properties of plagioclase and pyroxene mixures and the interpretation of lunar soil spectra. Icarus 72, 492-506.

Cruikshank, D. P. 1977. Radii and albedos of four Trojan asteroids and Jovian satellites 6 and 7. Icarus 30, 224-230.

Cruikshank, D. P. 1987. Dark matter in the Solar System. Adv. Space Res. 7, 109-120. 
Cruikshank, D. P. 1997 Organic matter in the solar system: From the meteorites to the Kuiper Belt. In From Stardust to Planetesimals (Y. J. Pendleton and A. G. G. M. Tielens, Eds.), pp. 315-333. Astron. Soc. Pacific Conf. Ser.

Cruikshank, D. P., C. M. Dalle Ore, T. L. Roush, T. C. Owen, T. R. Geballe, B. N. Khare, and C. de Bergh. Surface Compositions of the Icy Satellites of Saturn. In preparation.

Cruikshank, D. P., T. L. Roush, M. J. Bartholomew, T. R. Geballe, Y. J. Pendleton, S. M. White, J. F. Bell, III, J. K. Davies, T. C. Owen, C. de Bergh, D. J. Tholen, M. P. Bernstein, R. H. Brown, K A. Tryka, and C. M. Dalle Ore 1998. The composition of centaur 5145 Pholus. Icarus 135, 389-407.

Cruikshank, D. P. and B. N. Khare 2000. Planetary Surfaces of Low Albedo: Organic Material Throughout the Solar System. In Bioastronomy '99-A New Era in Bioastronomy (G. A. Lemarchand and K. J. Meech, Eds.), pp. 253-261. Astron. Soc. Pacific Conf. Series.

Cruikshank, D. P., K. Uchida, R. N. Clark, J. W. Salisbury, W. K. Hartmann, B. N. Khare, C. N. Matthews, R. L. Ludicky, C. Sagan, G. Strazzulla, M. J. Bartholomew, and E. T. Arakawa. Infrared spectra of organic solids for comparison with dark solar system bodies. In preparation.

Dalle Ore, C. M., D. P. Cruikshank, T. C. Owen, T. R. Geballe, T. L. Roush, B. N. Khare, and C. de Bergh 1999. Bull. Am. Astron. Soc. 31, 1073 (abstract).

Dumas, C., T. Owen, and M. A. Barucci 1998. Near-infrared spectroscopy of low-albedo surfaces of the Solar System: Search for the spectral signature of dark material. Icarus 133, $221-232$.

Dunlap, J. L., and T. Gehrels 1969. Minor planets. III. Lightcurves of a Trojan asteroid. Astron. J. 74, 797-803.

Fink, U., M. Hoffmann, W. Grundy, M. Hicks, and W. Sears 1992. The steep red spectrum of $1992 \mathrm{AD}$ : An asteroid covered with organic material? Icarus 97, 145-149.

Gaffey, M. J. 1976. Spectral reflectance characteristics of the meteorite classes. J. Geophys. Res. 81, 905-920.

Gaffey, M. J., J. F. Bell, and D. P. Cruikshank 1989. Reflectance spectroscopy and asteroid surface mineralogy. In Asteroids II (R. P. Binzel, T. Gehrels, and M. S. Matthews, Eds.), pp 98-127. Univ. of Arizona Press, Tucson.

Gradie, J., and Veverka, J. 1980. The composition of the Trojan asteroids. Nature 283, 840-842. 
Hapke, B. 1981. Bidirectional reflectance spectroscopy, 1. Theory. J. Geophys. Res. 86, 3039-3054.

Hapke, B. 1993. Theory of Reflectance and Emittance Spectroscopy. 455 pp. Cambridge Univ. Press, New York.

Hartmann, W. K. 1980. Surface evolution of two-component stone/ice bodies in the Jupiter region. Icarus 44, 441-453.

Hartmann, W. K., and D. P. Cruikshank 1978. The nature of Trojan asteroid 624 Hektor. Icarus 36, 353-366.

Hartmann, W. K., and D. P. Cruikshank 1980. Hektor, the largest highly elongated asteroid. Science 207, 976-977.

Hinrichs, J .L., P .G. Lucey, M .S. Robinson, A. Meibom, and A. N. Krot 1999a. Implications of temperature dependent near-IR spectral properties of common minerals and meteorites for remote sensing of asteroids, Geophys. Res. Lett. 26, 1661-1664.

Hinrichs, J. L., P. G. Lucey, M. S. Robinson, A. Meibom, and A. N. Krot $1999 \mathrm{~b}$. Temperature dependent near-infrared spectra of olivine and $\mathrm{H} 5$ ordinary chondrites. Lunar Planetary Sci, 30, abstract 1505.

Hinrichs, J. L., P. G. Lucey, A. Meibom, N. M. Domergue-Schmidt, G. J. Taylor, T. Burbine, and D. D. McCord 2000. Near-IR reflectance sensitivity: Lunar soils, meteorites, and minerals, Lunar Planetary Sci., 31, abstract 1521.

Hiroi, T., M. E. Zolensky, C. M. Pieters, and M. E. Lipschutz 1996. Thermal metamorphism of the C, G., B, and F asteroids seen from the $0.7 \mu \mathrm{m}, 3 \mu \mathrm{m}$, and UV absorption strengths in comparison with carbonaceous chondrites. Meteoritics and Planetary Science 31, 321-327.

Jewitt, D. C., and J. X. Luu 1990. CCD spectra of asteroids. II. The Trojans as spectral analogs of cometary nuclei. Astron. J. 100, 933-944.

Jones, T. D., L. A. Lebofsky, J. S. Lewis, and M. S. Marley 1990. The composition and origin of the C, P, and D asteroids: Water as a tracer of thermal evolution in the outer belt. Icarus 88, 172-192.

Khare, B. N., C. Sagan, E. T. Arakawa, F. Suits, T. A. Callcot, and M. W. Williams 1984. Optical constants of organic tholins produced in a simulated Titanian atmosphere: From soft $x$-ray to microwave frequencies. Icarus 60, 127-137.

Khare, B. N., W. R. Thompson, L. Cheng, C. Chyḅa, C. Sagan, E. T. Arakawa, C. Meisse, and P. Tuminello 1993. Production and optical constants of ice tholin from charged particle irradiation of $(1: 6) \mathrm{C}_{2} \mathrm{H}_{6} / \mathrm{H}_{2} \mathrm{O}$ at $77 \mathrm{~K}$. Icarus 103, 290-300. 
Khare. B. N., C. Sagan, W. R. Thompson, E. T. Arakawa, C. Meisse, and P. S. Tuminello 1994a. Optical properties of poly-HCN and their astronomical applications. Can.J.

Chem. 72, 678-694.

Khare. B. N., C. Sagan, W. R. Thompson, E. T. Arakawa, C. Meisse, and P. S. Tuminello 1994b. Optical constants of Triton tholin: Preliminary results. Bull. Am. Astron. Soc. 26, 1176-1177 (abstract).

Khare, B. N., W. R. Thompson, C. Sagan, E. T. Arakawa, C. Meisse, and I. Gilmour 1990. Optical constants of kerogen from 0.15 to $40 \mu \mathrm{m}$ : Comparison with meteoritic organics. In First Int. Conf. on Lab. Res. for Planetary Atmospheres, NASA CP-3077, 340-356, NASA, Washington, DC.

Lebofsky, L. A., T. D. Jones, P. D. Owensby, M. A. Feierberg, and G. J. Consolmagno 1990. The nature of low-albedo asteroids from 3- $\mu \mathrm{m}$ multi-color photometry. Icarus 83 , 16-26.

Lucey, P. G. 1998. Model near-infrared optical constants of olivine and pyroxene as a function of iron content. J., Geophys. Res. 103, 1703-1713.

Luu, J. 1991. CCD photomery and spectroscopy of the outer jovian satellites. Astron. J. $103,1213-1225$.

Luu, J., D. Jewitt, and E. Cloutis 1994. Near-infrared spectroscopy of primitive Solar System objects. Icarus 109, 133-144.

Maurette, M., C. Engrand, and G. Kurat 1996. Collection and microanalysis of Antarctic micrometeorites. In Physics, Chemistry, and Dynamics of Interplanetary Dust (B. A. A. Gustafson and M. S. Hanner, Eds.), pp 265-273. ASP Conf. Ser. 104.

McDonald, G. D., W. R. Thompson, M. Heinrich, B. N. Khare, and C. Sagan 1994. Chemical investigation of Titan and Triton tholins. Icarus 108, 137-145.

McDonald, G. D., L. J. Whited, C. DeRuiter, B. N. Khare, A. Patniak, and C. Sagan 1996. Production and chemical analysis of cometary ice tholins. Icarus 122, 107-117.

Moroz, L. V., G. Amold, A. V. Korochantsev, and R. Wäsch 1998. Natural solid bitumens as possible analogs for cometary and asteroid organics. Icarus 134, 253-268.

Moroz, L. V., and G. Amold 1999. Influence of spectrally neutral components on relative band contrasts in intimate mixtures and implication for remote sensing: 1 . Nonlinear mixing modeling. J. Geophys. Res. 104, 14,109-14,121. 
Moroz, L. V., U. Schade, and R. Wäsch 2000. Reflectance spectra of olivineorthopyroxene-bearing assemblages at decreased temperatures: Implication for remote sensing of asteroids. Icarus 147, 79-93.

Mueller, B. E. A., D. J. Tholen, W. K. Hartmann, and D. P. Cruikshank 1992. Extraordinary colors of asteroidal object (5145) 1992 AD. Icarus 97, 150-154.

Owen, T. C., D. P. Cruikshank, C. M. Dalle Ore, T. R. Geballe, T. L. Roush, and C. de Bergh 1999. Detection of water ice on Satum's satellite Phoebe. Icarus 140, 379-382.

Owen, T. C., D. P. Cruikshank, C. M. Dalle Ore, T. R. Geballe, T. L. Roush, C. de Bergh, Y. J. Pendleton, and B. N. Khare. Decoding the Domino: The Dark Side of Iapetus. Icarus, in press, 2000,

Pieters, C. M. 1993. Compositional diversity and stratigraphy of the lunar crust derived from reflectance spectroscopy. In Remote Geochemical Analysis: Elemental and Mineralogical Composition (C. M. Pieters and P. A. J. Englert, Eds.), pp. 309-339. Cambridge Univ. Press, Cambridge.

Pieters, C. M., L. A. Taylor, S. K. Noble, L. P. Keller, B. Hapke, R. V. Morris, C. C. Allen, D. S. McKay, and S. Wentworth 2000. Space weathering on airless bodies: Resolving a mystery with lunar samples. Meteorit. Planet. Sci. 35, 1101-1107.

Pollack, J. B., D. Hollenbach, S. Beckwith, D. P. Simonelli, T. Roush, W. Fong 1994. Composition and radiative properties of grains in molecular clouds and accretion disks. Astrophys. J. 421, 615-639.

Roush, T. L. 1984. Effects of Temperature on Mafic Mineral Absorption Features, M.S. Thesis, University of Hawaii, Honolulu, 129pp.

Roush, T. L. 1987. Characterization of the spectral reflectance of mafic silicates, hydrated silicates, and hydrated silicate-water ice mixtures in the 0.6 to $4.5 \mu \mathrm{m}$ wavelength region and applications to planetary science. Thesis, Univ. of Hawaii. 130 pp.

Roush, T. L. and R. B. Singer 1987. Possible temperature variation effects on the interpretation of spatially resolved reflectance observations of asteroid surfaces, Icarus 69, 571-574.

Salisbury, J. W., D. M. D'Aria, and E. Jarosewich 1991. Midinfrared (2.5-13.5 $\mu \mathrm{m})$ reflectance spectra of powdered stony meteorites. Icarus 92, 280-297.

Sandford, S. A. 1984. Infrared transmission spectra from 2.5 to $25 \mu \mathrm{m}$ of various meteorite classes. Icarus 60, 115-126. 
Sandford, S. A. 1993. The mid-infrared transmission spectra of Antarctic urelites. Meteoritics 28, 579-585.

Schade, U. and R. Wäsch 1999. NIR reflectance spectroscopy of mafic minerals in the temperature region between 80 and 473K, Adv. Space. Res. 23, 1253-1256.

Singer, R. B. and T. L. Roush 1985 . Effects of temperature on remotely sensed mineral absorption features, J. Geophys. Res. 90, 12,434-12,444.

Strazzulla, G., P. Massimino, F. Spinella, L. Calcagno, and A. M. Foti 1988. IR spectra of irradiated organic materials. Infrared Phys. 28, 183-188.

Thompson. W. R., B. G. J. P. T. Murray, B. N. Khare, and C. Sagan 1987. Coloration and darkening of methane clathrate and other ices by charged particle irradiation: Applications to the outer Solar System. J. Geophys. Res., 92, 14,933-14,947.

Veeder, G. J., D. L. Matson, and G. Hoover 1983. Infrared (JHK) photometry of Asteroids. II. Astron. J. 88, 1060-1063.

Vilas, F., S. M. Larson, E. C. Hatch, and K. S. Jarvis 1993. CCD reflectance spectra of selected asteroids. П. Low-albedo asteroid spectra and data extraction techniques. Icarus $105,67-78$.

Vilas, F., K. S. Jarvis, and M. J. Gaffey 1994. Iron alteration minerals in the visible and near infrared spectra of low albedo asteroids. Icarus 109, 274-283.

Wooden, D. H., H. M. Butner, D. E. Harker, and C. E. Woodward 2000. Mg-rich silicate crystals in Comet Hale-Bopp: ISM relics or solar nebula condensates? Icarus 143, 126137.

Zellner, B., D. J. Tholen, and E. F. Tedesco 1985. The eight-color asteroid survey: Results for 589 minor planets. Icarus 61, 355-416.

Zolensky, M., and H. Y. McSween, Jr. 1988. Aqueous Alteration. In Meteorites and the Early Solar System (J. F. Kerridge and M. S. Matthews, Eds.), pp 114-143. Univ. of Arizona Press, Tucson.

\section{FIGURE CAPTIONS}

Figure 1. The spectrum of 624 Hektor, 2.4-3.6 $\mu \mathrm{m}$, obtained October 28, 1998. The region $2.57-2.83 \mu \mathrm{m}$ is heavily obscured by telluric $\mathrm{H}_{2} \mathrm{O}$ vapor. The flux scale is in $\mathrm{W} / \mathrm{m}^{2} \mu \mathrm{m}$. At the time of the observation, Hektor was 5.194 AU from the Sun and 4.556 AU from Earth. The solar phase angle was $9.0 \mathrm{deg}$.

Figure 2. Upper panel: the composite spectrum of Hektor from the sources indicated in the text, including a segment (inset) of the CCD spectrum by Vilas et al. (1993). The 
ECAS $(-0.3-1.1 \mu \mathrm{m})$ data points and errors are from Zellner et al. (1985), the three large diamonds are JHK photometry from Veeder et al. (1983), the segment from 1.5-2.4 is the previously unpublished IRTF data set (Table I and text), and the segment 2.4-3.6 $\mu \mathrm{m}$ is from the 1998 UKIRT data (Table I and text). The gap in the UKIRT data from 2.55 to $2.85 \mu \mathrm{m}$ is a region of strong telluric absorption. Lower panel: the composite Hektor spectrum without error bars, shown with the spectrum of the low-albedo hemisphere of Iapetus (Owen et al. 2000) for comparison.

Figure 3. The two intimate mixture models shown here incorporate only pyroxene ( $80 \%$ $\mathrm{Mg}$ ), amorphous carbon, and graphite in the proportions shown. The figures in parentheses are the grain diameters in micrometers. Both of the models deviate upward from the Hektor data at $\lambda>2.5 \mu \mathrm{m}$, and are inferior to other models shown, notably in Figure 5.

Figure 4. Intimate mixture models shown here include varying amounts of water ice, evident in the absorption bands at 2.0 and $3 \mu \mathrm{m}$. Pyx = pyroxene ( $80 \% \mathrm{Mg}$ in all cases), $\mathrm{AC}=$ amorphous carbon, Serp $=$ serpentine, $\mathrm{Ol}=$ olivine. The figures in parentheses are the grain diameters in micrometers of the individual components.

Figure 5. Intimate mixture models of pyroxene, amorphous carbon, and serpentine with varying amounts of each component. The effect of the different $\mathrm{Mg}$ content of pyroxenes is shown. The top panel uses pyroxene with $80 \% \mathrm{Mg}$, the middle panel is $70 \% \mathrm{Mg}$, and the lower panel is $60 \% \mathrm{Mg}$; all optical constants for the pyroxenes were taken from the Jena group web site (footnote to Table III).

Figure 6. Laboratory biconical reflectance spectra of three meteoritic materials. (Cruikshank et al., in preparation)

Figure 7. Two models in which the three components are spatially segregated. Pyx 80 is the Jena pyroxene with $80 \% \mathrm{Mg}$, and Pyx 60 has $60 \% \mathrm{Mg}$. AC = amorphous carbon, Serp $=$ serpentine. The numbers in parentheses and separated by colons give the percentages of the surface covered by the three components, respectively. 


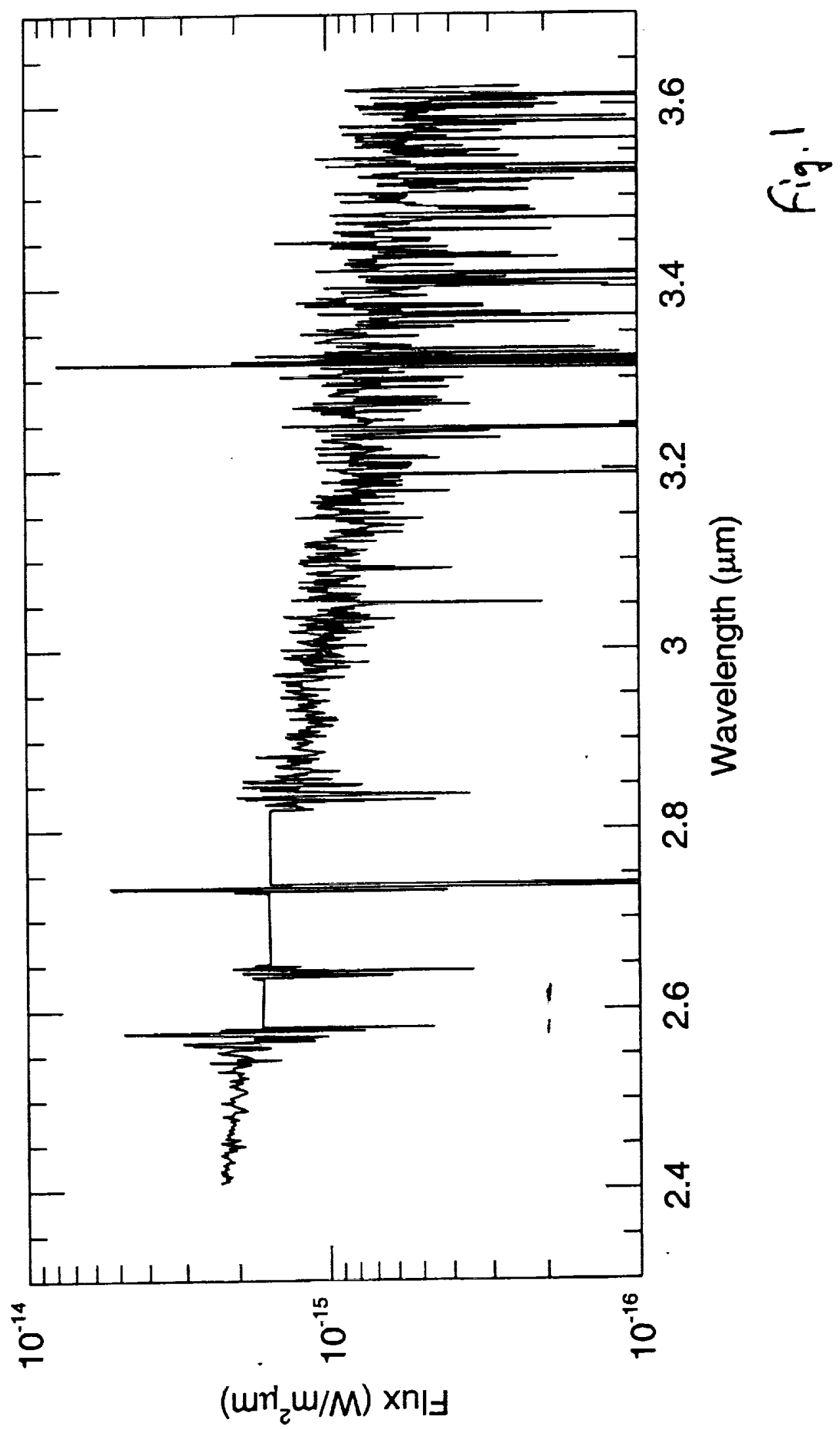




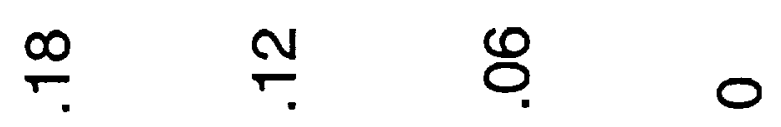

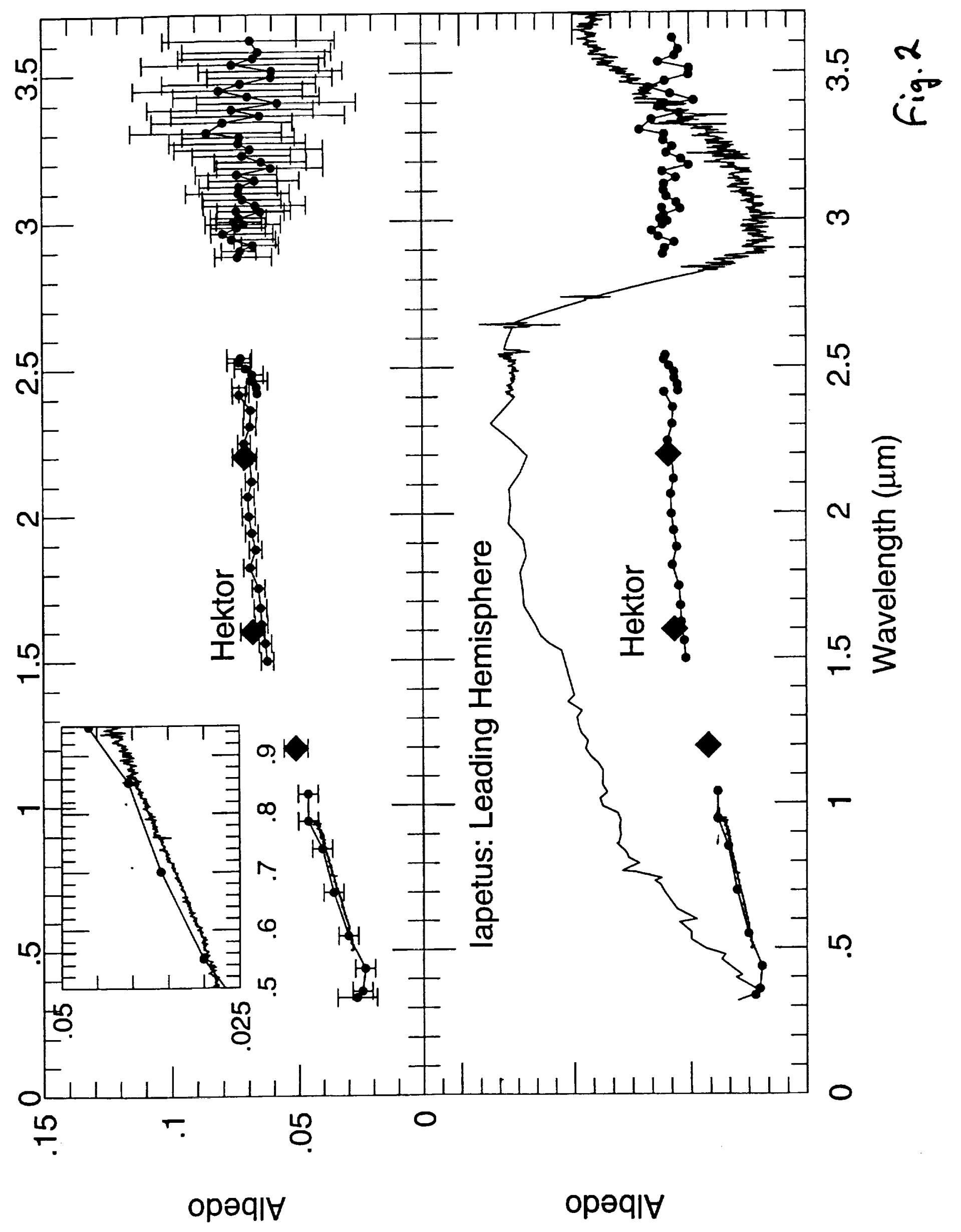




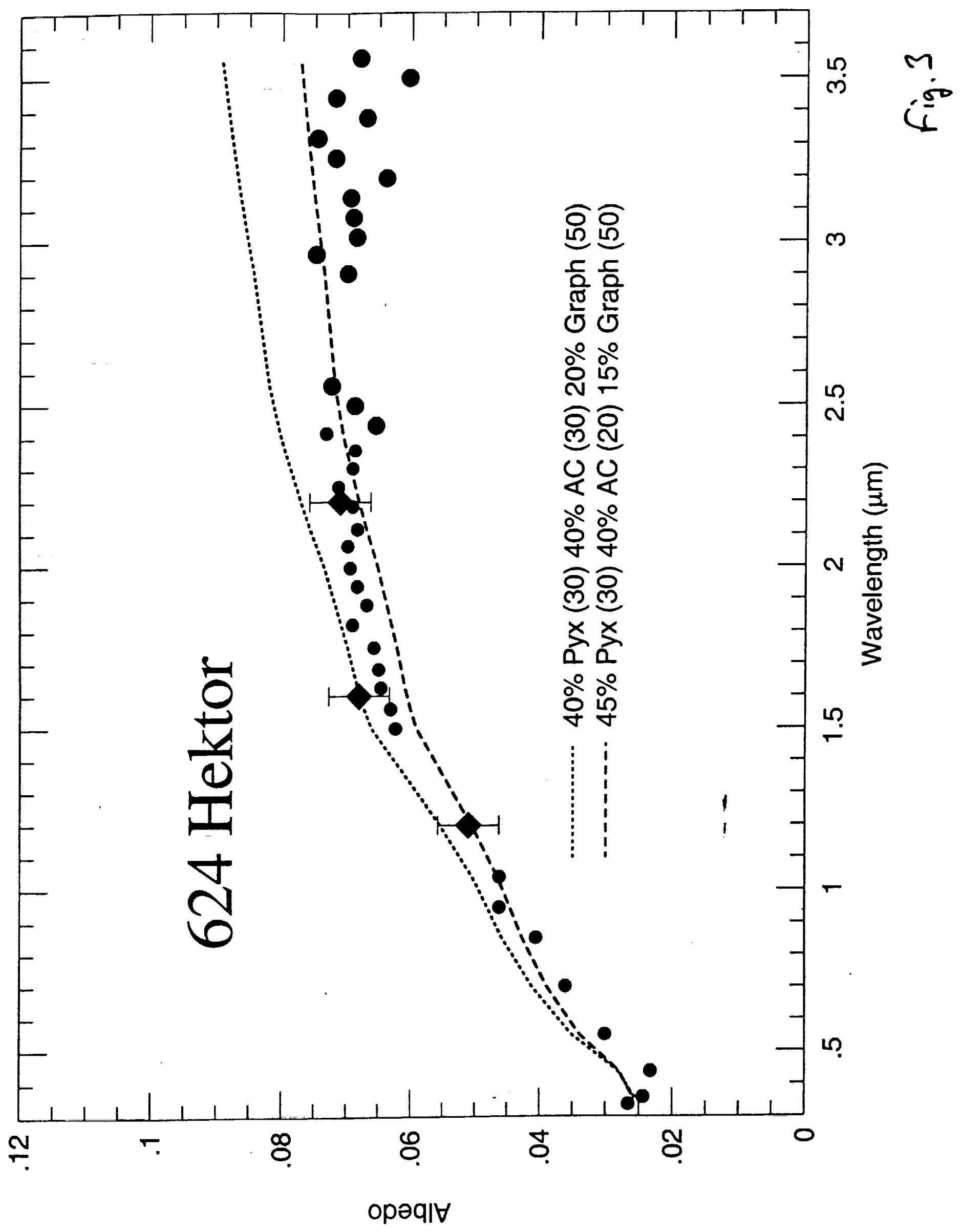




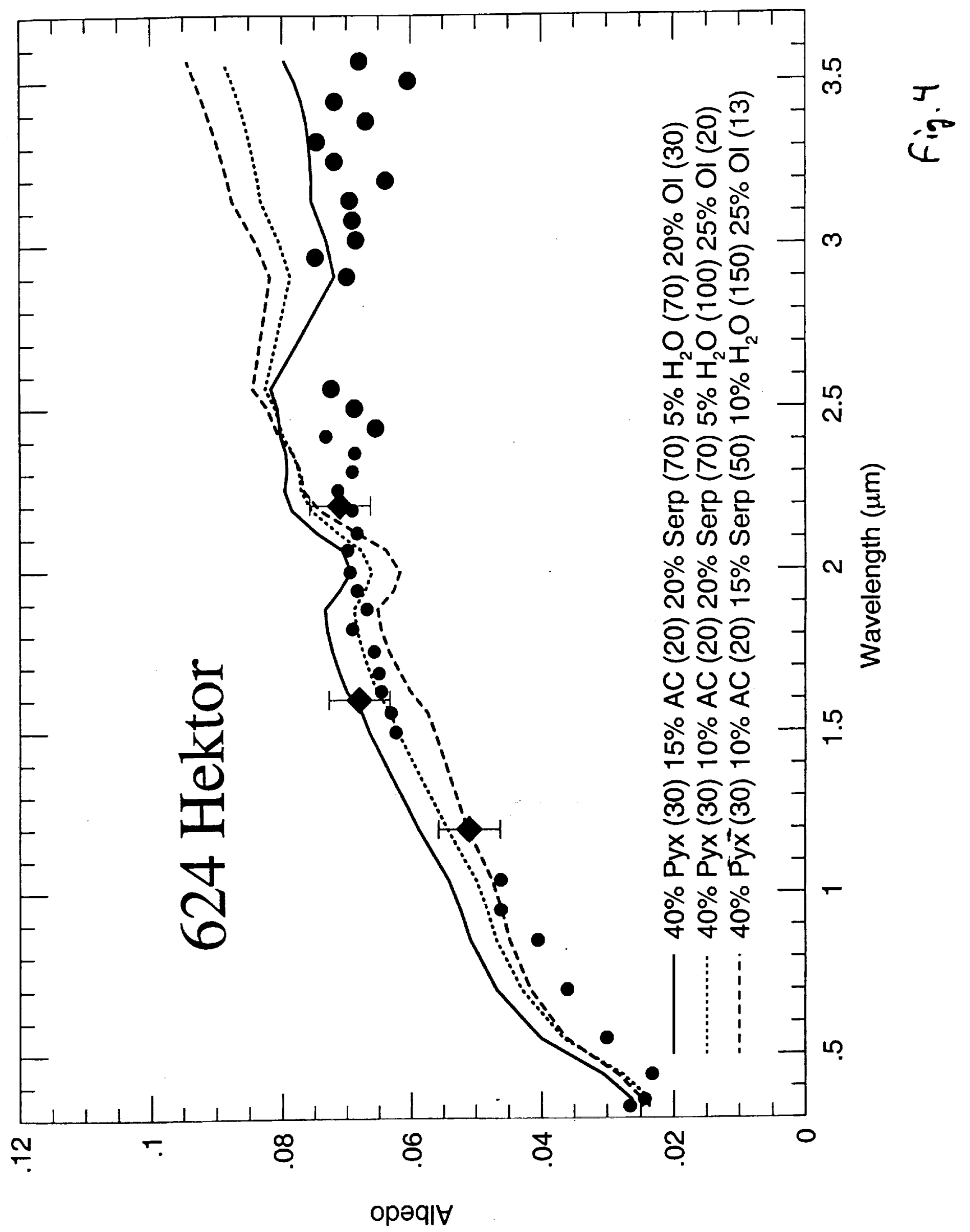




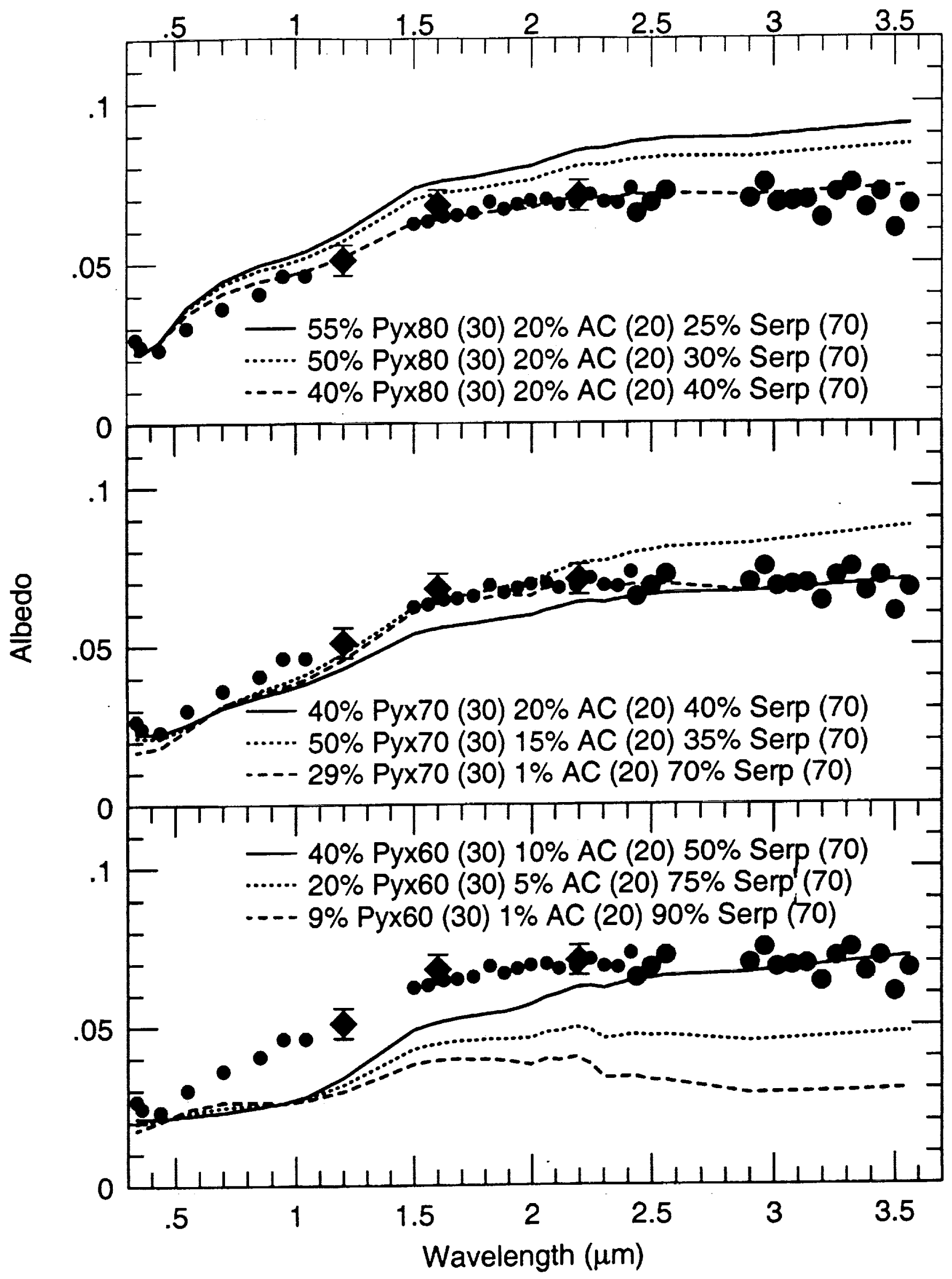

Fig. 5 


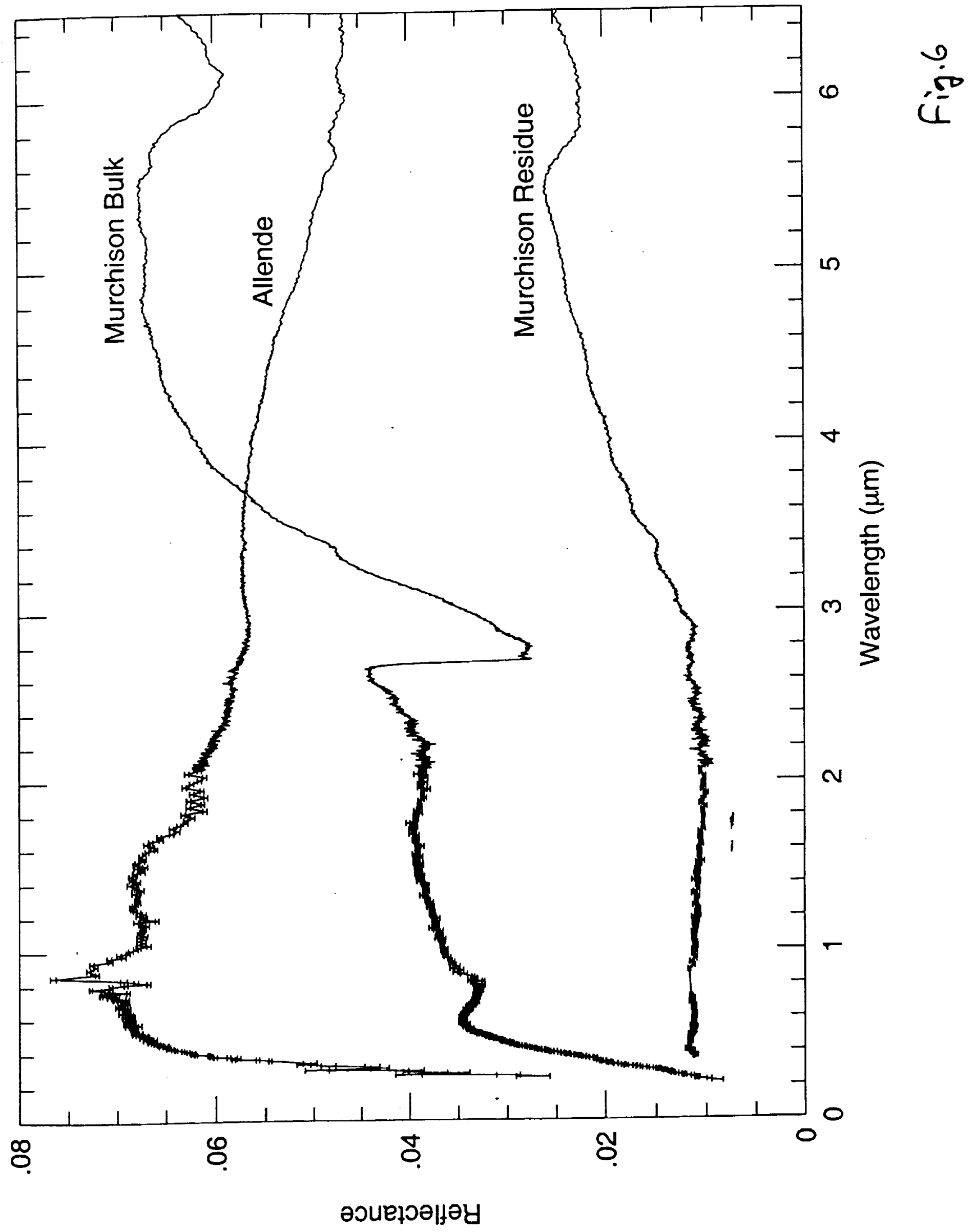




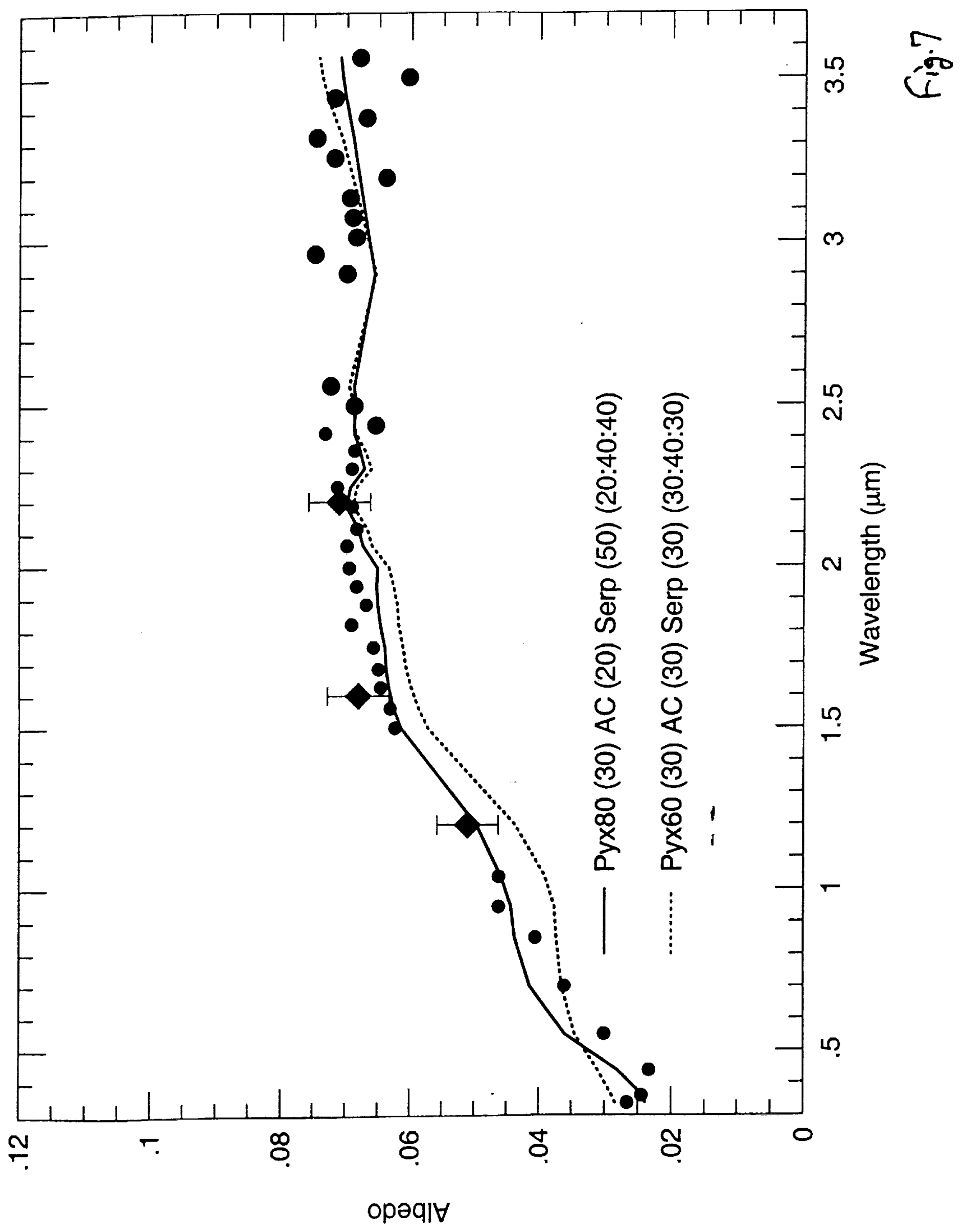

